Año 11.

Revista de Investigación

Núm. 28

Académica sin Frontera

ISSN: 2007-8870

\title{
http://revistainvestigacionacademicasinfrontera.com
}

Recibido el 29 de mayo de 2018. Dictaminado mediante arbitraje favorablemente 1 de noviembre de 2018.

\section{Estructura nodal exploratoria de la administración de la seguridad migratoria en los medios impresos}

\section{Exploratory nodal structure of the administration of migratory security in the printed media}

Joel Martínez-Bello ${ }^{1}$, Christian Bucio-Pacheco ${ }^{2}$, José Alfonso Aguilar-Fuentes ${ }^{3}$, Francisco Javier Rosas-Ferrusca ${ }^{4}$, Wilfrido Isidro Aldana-Balderas ${ }^{5}$, Adriana Vanessa Blanes-

Ugarte $^{6}$, Cruz García-Lirios ${ }^{7}$

Resumen -El objetivo del presente estudio es establecer un ciclo sociopsicológico de la inseguridad relativa a la migración y su correspondiente índice para medir el grado de mediatización de la prensa en torno a las notas periodísticas sobre la problemática. Para tal propósito, se utilizó el ciclo de Kondratieff y la Teoría del Establecimiento de la Agenda de McCombs. Se consideraron diez categorías para el análisis del contenido de las noticias y su ponderación en la estimación del índice. El índice de mediatización fue considerado bajo a partir del cual se dedujo que el sesgo informativo de la prensa no influiría en la opinión pública. Sin embargo, al enfocarse la mediatización de los periódicos en la categoría peligro esta permitió abrir la discusión en torno a las dimensiones y niveles de análisis de las categorías.

Palabras claves -Ciclos, Inseguridad, Migración, Mediatización, Contextualización, Enmarcado e Intensificación.

\footnotetext{
1 UAEMEX, Huehuetoca: jmartinezb@uaemex.mx

2 UAEMEX, Huehuetoca: cbuciop@uaemex.mx

3 UAEMEX, Huehuetoca: jaaguilarf@uaemex.mx

${ }^{4}$ UAEMEX, Toluca: fjrosasf@uaemex.mx

${ }^{5}$ UAEMEX, Huehuetoca: wialdanab@uaemex.mx

${ }^{6}$ UAEMEX, Huehuetoca: avblabesu@uaemex.mx

${ }^{7}$ CEPS, Cuernavaca: garcialirios@ceps.mx
} 


\title{
http://revistainvestigacionacademicasinfrontera.com
}

\begin{abstract}
The objective of the present study is to establish a socio-psychological cycle of the insecurity regarding the migration and its corresponding index to measure the degree of annexation of the press around journalistic notes on the problematic one. For such intention, it was used the cycle of Kondratieff and the Theory of the Establishment of the Setting of MaCombs. Ten categories for the analysis of the content of the news and their consideration in the estimation of the index were considered. The annexation index was considered low and from which it was deduced that the informative slant of the press would not influence in the public opinion. Nevertheless, when focusing the annexation of newspapers in the category danger this allowed open to the discussion around the dimensions and levels of analysis of the categories.
\end{abstract}

Key words -Cycles, Insecurity, Migration, Mediation, Setting, Framing and Priming.

\section{Introducción}

El análisis de la inseguridad puede realizarse a partir de sus efectos migratorios. Los estudios psicosociológicos de la inseguridad la han definido como un ciclo descendente de agresión, injuria, injusticia, ansiedad, peligro, desesperación, pánico, depresión, venganza y discriminación. Al ser la inseguridad un indicador negativo de los ciclos económicos, políticos y sociales incrementa los flujos migratorios globales y locales. Al estar en medio de la descapitalización, la ingobernabilidad y el desempleo, la inseguridad modera el impacto de estos factores sobre los flujos migratorios.

La inseguridad es parte de los ciclos económicos, políticos y sociales. A partir de estadísticas de inversión, legislaciones y movilizaciones, Kondratieff (1920/2004) estableció cuatro ciclos consecutivos de 55, 45, 50 y 64 años en el que se aprecian ascensos; prosperidad económica, legitimidad política y pleno empleo, posteriores descensos; descapitalización, ingobernabilidad y desempleo.

A partir de los ciclos Kondratieff, es posible ubicar los eventos socioeconómicos y sociopolíticos en el ascenso o descenso de la curva cíclica. La figura 2 muestra los acontecimientos que han impactado la historia de la humanidad. En torno a la inseguridad, los ciclos Kondratieff la consideran como una fase cíclica descendiente.

En este sentido, la inseguridad, desde la óptica de Kondratieff, es una consecuencia de la descapitalización, la ingobernabilidad y el desempleo. Asociada con la violencia, la inseguridad inicia con un evento considerado agresivo en el cual se desatará un conflicto de intereses.

Los ciclos económicos, políticos y sociales parecen reactivarse a partir de conflictos en los que el indicador principal es la inseguridad. En esta fase del ciclo, inseguridad y conflicto 


\section{http://revistainvestigacionacademicasinfrontera.com}

son sinónimos. En tanto que el conflicto devela las relaciones asimétricas, unos se observan superiores a otros que se ven a sí mismos como agraviados, la inseguridad avizora consecuencias ascendentes que podrían terminar en la reconciliación o en violencia entre las partes.

La reconciliación es un acuerdo entre las partes dispuestas a establecer relaciones simétricas, unos se ven como iguales a otros que exigían justicia. La violencia refiere a la construcción de enemigos justificada por la magnitud de agravios entre las partes.

No obstante, la inseguridad alude tanto al ascenso (reconciliación) como al descenso (violencia). Puesto que la inseguridad es una fase cíclica, la comunicación entre las partes es la estrategia principal para superar el conflicto de intereses. Una vez identificadas y salvadas las barreras para la comunicación, la inseguridad es sustituida negociados entre las partes que iniciaran pactos, acuerdos y tratados de no agresión.

\section{Migración e Inseguridad como fases del ciclo socioeconómico político}

Sin embargo, los conflictos socioeconómicos y sociopolíticos tales como el desempleo y el narcotráfico parecen denostar la comunicación, negociación y acuerdos entre las partes. Cuando éstos se agudizan, la migración definida como la redistribución de exiliados en zonas de inversión, gobernabilidad y empleo lejanos a la felicidad, pero cercanas a estabilidad, subyace como una alternativa de solución ante las crisis económico-políticas y sociales de las zonas de exilio.

Los flujos migratorios globales de los países ubicados en el descenso de sus ciclos económicos, políticos y sociales a los países con ciclos prósperos. Puede observarse que la migración, en América Latina, tiene como principal causa las crisis económicas conocidas como descapitalización y las crisis políticas conocidas como ingobernabilidad. Ambas contribuyen al surgimiento de flujos migratorios incentivados por la inseguridad en los países expulsores e incentivados por la flexibilización del empleo en los países receptores.

En el caso de México, los flujos migratorios tienen su origen en zonas demográficas urbanas del 40 al 50 por ciento, lo cual indica que las sequías y la inseguridad están expulsando a los campesinos a otras regiones del país y los Estados Unidos de América (USA por sus siglas en inglés).

No obstante, la migración interna parece redistribuir a la población en zonas urbano-turísticas como son los casos de Baja California Sur y Quintana Roo. La densidad poblacional y la disponibilidad de los recursos naturales, principalmente hídricos en las zonas urbanoturísticas, no incide en la expulsión, sino en la recepción de migrantes. 


\section{http://revistainvestigacionacademicasinfrontera.com}

Los municipios en donde la violencia parece no tener un ciclo descendente hacia la reconciliación. Por el contrario, el ciclo de violencia parece dirigirse hacia un círculo vicioso de agresión más que de reconciliación y prevención del delito.

Si se observan los conglomerados municipales más violentos y se comparan con las áreas de influencia de los cárteles, es posible observar que los conflictos por el mercado de consumo entre los cárteles del narcotráfico parecen incidir en la espiral de violencia sin visos de cambio hacia la reconciliación y la prevención del delito.

No obstante que la inseguridad es una fase de los ciclos económicos, políticos y sociales, en el caso de México, el proceso de violencia parece incrementarse y no tener fin. Incluso, representa una amenaza para la seguridad nacional de Estados Unidos y América Latina.

\section{Los estudios comunicológicos de la mediatización}

Los estudios comunicológicos de la mediatización se han configurado en tres tradiciones a partir de los efectos, la recepción y la socialización de los medios masivos de comunicación (Ibarra, 2001; Fernández, 2010). La diversidad de teorías, métodos y técnicas de investigación permite la construcción de modelos integrales en los que se complementarían los conceptos tales como; los contextos (settings), encuadres (framings), intensidades y direcciones (primings) de los mensajes (McCombs, 1972). Es decir, los medios de comunicación influyen sobre la opinión pública a través de la mediatización (Serrano, 1986: p. 16). Los medios tienden a difundir más imágenes que conceptos (Sartori, 1997). Se trata de procesos periféricos de recepción, aceptación, decisión y consumo afectivos más que procesos centrales racionales (Petty y Cacioppo, 1986a; 1989b). Una representación racional del entorno y de sí mismo sería el antecedente de la persuasión (Cacioppo, Petty, Feng y Rodríguez, 1986; Cacioppo y Petty, 1989; Briñol, Gallardo, Horcajo, De la Corte, Valle y Díaz, 2004). Si el impacto de la información sobre los estilos de vida es indirecto (Gunter, 2008), la mediatización regula el impacto de los hechos sobre la identidad (Figueras, 2008). Al tergiversar los eventos, manipular las situaciones o fragmentar los hechos, los medios de comunicación moderan el impacto de los hechos sobre las decisiones públicas y privadas. Se trata de la mediación social que emerge ante las asimetrías de intereses como factor de cambio intercultural (Sobrados y Muños, 2009).

En América Latina, la mediatización se estudia desde tres orientaciones; la europea histórica filosófica, la norteamericana positivista sistémica y la europea semiótica estructuralista. De León (2008) plantea tres dimensiones derivadas de estas orientaciones. 


\section{http://revistainvestigacionacademicasinfrontera.com}

- Producción y distribución del mensaje.

- Análisis del contenido de la información.

- Recepción y apropiación comunicativa.

○ Uso social mediático

- Industrialización cultural

- Recepción activa

- Identidades complejas

- Sistemas multimediacionales

A partir de los estudios referidos, la mediatización puede ser definida como la industrialización, producción, difusión, recepción e identidad en torno a mensajes sobre sustentabilidad para la formación de opinión pública que minimiza o maximiza la interdependencia entre las situaciones de los recursos y los estilos de vida.

\section{Teoría del Establecimiento de la Agenda}

La Teoría del Establecimiento de la Agenda (TEA) asegura que los medios de comunicación difunden temas de violencia a partir de sus intereses y no de la tendencia de casos del fuero común o federal. Dicha prevalencia, tiene un efecto sobre la percepción de inseguridad de las audiencias y en el caso de los medios impresos, el efecto es el discurso de sus lectores sobre la violencia y particularmente, los homicidios dolosos.

Los postulados de la Teoría del Establecimiento de la Agenda permiten explicar el proceso de construcción de la agenda mediática, pública y sobre todo política en torno a la inseguridad, la violencia, los homicidios, los perfiles y la impunidad.

Los estudios mediáticos han demostrado la selección, fragmentación y sesgo del ejercicio periodístico con estudios de sondeo simultáneo en el que las percepciones de los encuestados son una extensión de la agenda de los medios. Por otra parte, los experimentos de recepción y percepción corroboran no sólo el sesgo informático, sino además su poder de influir en la opinión pública.

No obstante, la TEA refiere solamente al sesgo informativo sin precisar un tiempo y espacio definidos para su comprobación empírica. En efecto, la tendencia ha sido medir simultáneamente, durante un lapso determinado, el sesgo mediático y la influencia en la percepción de la gente. 


\section{http://revistainvestigacionacademicasinfrontera.com}

Sin embargo, no es posible, realizar dos diagnósticos simultáneos de los hechos y concluir que existe una relación directa y significativa entre ellos. Si partimos de la premisa en torno a la cual un hecho es observable simultáneamente más de una vez, entonces tendríamos que pensar que la percepción si y sólo si está influida por los medios olvidando que puede estar influida por el hecho en sí, por otros acontecimientos relacionados, por experiencias directas, indirectas e incluso por otras notas informativas.

El mismo Maxwell McCombs (1972) sostiene que el sesgo informativo es inherente al ejercicio periodístico y esto significa que en realidad los medios no influyen directamente en la agenda-setting pública. Es decir, los medios son sólo intermediarios de los errores del ejercicio periodístico.

No obstante, Cervantes (1999: p. 141) crítica el planteamiento de McCombs en torno al establecimiento de la agenda-setting como fases no inductivas en las que sólo se consideran las noticias externas susceptibles de ser codificadas para demostrar la incidencia de los medios de comunicación en la opinión pública.

La Teoría del Establecimiento de la Agenda estaría cercana al análisis de las noticias internacionales que la opinión pública no puede conocer directamente y por ello se ve sumamente influenciada por los medios de comunicación dado que otras fuentes de información, incluso internet, no ofrecen contenidos cercanos al entendimiento de las personas comunes y corrientes que aprenden con base en imágenes más que con base en discursos estructurados o razonamientos lógicos científicos (Penalva, 1999: p. 159). Al construir una agenda mediática, los medios de comunicación construyen una agenda pública y política esencial para el Estado (Vázquez, 2004: p. 268). Es decir, los medios de comunicación utilizan marcos de referencia en los que la opinión pública se basa para construir su agenda de discusión pública. Se trata de atributos en torno a un tema que orientan la percepción, selección y recepción de la información por parte de las audiencias. El establecimiento de la agenda es un efecto de resonancia informativa en el que los medios emiten temas que a posteriori las audiencias amplificarán o disminuirán su relevancia, pero en definitiva incluirán en su agenda de discusión una vez que los medios se han encargado de difundir la noticia (García (2007: p. 31).

En este sentido, la agenda es una colección de temas compartidos por comunicadores, políticos y audiencias. No obstante, los estudios sobre el establecimiento de la agenda se enfocan en el proceso por el cual los medios de comunicación seleccionan los temas que las 


\section{http://revistainvestigacionacademicasinfrontera.com}

audiencias recepcionaran como de suma importancia y posteriormente discutirán con base en los conceptos difundidos por los medios (Muñiz, 2007: p. 92).

De León (2008: p. 166) sostiene que los medios de comunicación invisten de atributos los temas para facilitar su inclusión en la agenda pública. A través de los titulares y encabezados, los medios masivos de comunicación difunden expectativas en sus audiencias. Esto corrobora la hipótesis en torno a la cual los medios de comunicación influyen en la sociedad produciendo temas y colocándolos en la agenda de discusión pública. Los medios de comunicación masiva determinan y dictan los temas que la gente comentará. La opinión pública construirá percepciones sobre la importancia de los temas expuestos en los medios. Posteriormente, la gente comentará los temas incluso con las palabras utilizados por los profesionales de la comunicación en televisión, radio, prensa e internet (Igartua, Muñiz, Otero, Cheng y Gómez, 2008: p. 5).

Luengo (2009: p. 114) relaciona el establecimiento de la agenda con la formación de actitudes y decisiones de discusión en torno a los temas seleccionados por los medios y aceptados por la opinión pública como los asuntos públicos de mayor interés e importancia. Se trata de un efecto mediático que construye la opinión pública a través de sus expectativas e intenciones de llevar a cabo una discusión pública al interior del grupo de referencia o pertenencia. El establecimiento de la agenda pública se construye con estrategias de contexto tales como; mayor primacia, cobertura, tiempo y espacio a noticias relativas. En esto consistiría el poder mediático ya que los medios de comunicación pueden enfatizar un tema sin tener que asumir riesgos (Obregón, Arroyave y Milena (2009: p. 24).

Ugarte, Menéndez y Cuesta (2009: p. 79) critican el énfasis político en los temas que permitieron corroborar la hipótesis del establecimiento de la agenda. Reducen a las audiencias a meros espectadores incapaces de seleccionar información y construir su agenda de discusión. Paradójicamente, McCombs, a decir de los autores, concluye perfilando la investigación hacia los efectos psicológicos de los medios de comunicación en la opinión pública. Finalmente, la agenda es un problema social, a menudo conflictivo, que ha recibido cobertura mediática sesgando la atención del público hacia determinados objetos o cuestiones de la escena política y social en los que el público confía y asigna importancia en función del grado de relevancia mediático (Chihú, 2011: p. 31). 


\section{http://revistainvestigacionacademicasinfrontera.com}

\section{Método}

Diseño. Se realizó un estudio exploratorio, retrospectivo y transversal en el que se analizaron las noticias relativas la inseguridad que experimentan los migrantes en su trayectoria y que ha sido reportada por la prensa nacional.

Muestra. Se seleccionaron 300 noticias de periódicos de circulación nacional. Se consideraron sólo aquellas notas informativas que documentaban extractos de entrevistas relativas a migrantes afectados por la inseguridad.

Categorías. La elaboración del presente estudio considero las fases de la inseguridad; agresión, injuria, injusticia, ansiedad, peligro, desesperación, pánico, depresión, venganza y discriminación.

- La agresión fue definida como un acto deliberado, alevoso y ventajoso de una persona o grupo expuesto en la prensa como delincuente hacia una persona o grupo migrante considerado como víctima.

- La injuria es un delito incentivado por alguna de las partes en conflicto de intereses y expuesta por la prensa como acusaciones directas e indirectas de una persona o grupo hacia otro individuo o grupo (Gutiérrez, 2004).

- La injusticia alude a las percepciones sesgadas de enjuiciamiento y condena de los migrantes agraviados en referencia a sus ofensores y cuyos resultados no les favorecen según la opinión de periodistas (Lozano, 2004).

- La ansiedad refiere a un estado emocional de bajo autocontrol en torno al cual los periodistas y reporteros atribuyen como causa psicológica de la comisión de un delito y como una consecuencia psicológica de las migrantes víctimas del delito (García, Martínez y Albar, 2002).

- El peligro incluye percepciones y sentimientos de impotencia de los migrantes ante los hechos delictivos en torno al cual, la prensa etiqueta a un espacio, proceso, persona o grupo.

- La desesperación es mediatizada como un estado de ánimo en el que las migrantes víctimas declaran a la prensa sus emociones relativas a buscar un ser querido raptado, recuperar el patrimonio que le han hurtado o revivir a la persona asesinada.

- El pánico alude a una emoción que la prensa califica como extrema para describir la supervivencia de las migrantes víctimas potenciales de la delincuencia (Pineda, 2007).

- La depresión denota un estado emocional en el que los migrantes víctimas o potenciales víctimas acuden a refugiarse para afrontar los delitos que han padecido 


\section{http://revistainvestigacionacademicasinfrontera.com}

y aquellos que estiman sufrir en el futuro según las noticias de la prensa (Francisco, García y Maya, 2001).

- La venganza es una emoción que la prensa identifica como un incentivo para la comisión de un delito por parte del migrante hacia raptores, homicidas, ladrones, embaucadores, estafadores o extorsionadores.

- La discriminación refiere a discursos y acciones que la prensa codifica como causas y efectos de la inseguridad en un espacio delimitado y tiempo determinado al termino de los cuales, los rotativos esperan una espiral de violencia.

Instrumentos. Se utilizaron matrices de análisis de contenido ponderativas en las que se incluye la fecha, titulo, extracto y clasificación de las noticias seleccionadas. Dicha matriz permite la suma de las ponderaciones asignadas a cada nota informativa. Una vez sumadas, se establece el Índice de Mediatización de la Inseguridad Migratoria (IMIM).

Codificación. A partir de que las noticias recaban y en muchos casos fundamentan el contexto, encuadre, intensidad y dirección de la información a partir de las declaraciones de los afectados, se asignó un valor de 0 a aquellas notas que no incluyen entrevistas, 1 a aquellas notas que incluyen declaraciones sobre inseguridad, 2 a aquellas notas que incluyen declaraciones sobre agresión, 3 a declaraciones de injuria, 4 a declaraciones de injusticia, 5 a declaraciones de ansiedad, 6 a declaraciones de peligro, 7 a declaraciones de pánico, 8 a declaraciones de depresión, 9 a declaraciones de venganza, 10 a declaraciones de discriminación. Si se trataba de una contextualización, se multiplicaba el total por 1, si se trataba de un enmarcado se multiplicaba por 2 y si se trataba de una propaganda se multiplicaba por 3. El criterio de multiplicación obedece a que la mediatización que consiste en contextualizar la noticia con datos tiene menor impacto que las noticias encuadradas en un aspecto socioeconómico o sociopolítico y aquellas que difunden propaganda dirigida al conflicto con miras al cambio social.

Análisis. Una vez ponderadas las noticias, fueron sumados sus codificaciones para ubicarlas en un subíndice de mediatización que se establece mediante el criterio de nula mediatización (cero puntos), muy baja mediatización (menos de 300), baja mediatización (entre 301 y 400), mediana mediatización (entre 401 y 500), alta mediatización (entre 501 y 600) muy alta mediatización (más de 600). Los criterios surgen a partir del concepto de Mediatización de la Inseguridad Migratoria en la que se sugiere un continuo de que va de la nulidad hasta la mediatización extrema. Es decir, la prensa recopila las declaraciones sobre agresión, injuria, 


\section{http://revistainvestigacionacademicasinfrontera.com}

injusticia, ansiedad, peligro, desesperación, pánico, depresión, venganza y discriminación que pueden indicar el nivel de inseguridad registrado por la prensa.

Se estimaron media, desviación, sesgo, curtosis y chi cuadrada para establecer las relaciones contingentes entre las categorías de contextualziación, enmarcado y propaganda con respecto a las subcategorias de inseguridad; agresión, injuria, injusticia, ansiedad, peligro, desesperación, pánico, depresión, venganza y discriminación.

Procedimiento. Se realizó una búsqueda avanzada a través de google.com. Los criterios fueron; periódicos de circulación nacional, fecha de la noticia dentro del umbral enero de 2012 a abril de 2018, encabezado de la noticia relacionado con la inseguridad y la migración. Posteriormente, se seleccionaron las notas informativas a partir de sus contenidos contextuales, enmarcados e intensificación de sus reportajes, opiniones, entrevistas o análisis. Se vació la información en matrices de análisis (ver anexo A1) y jueces expertos en las temáticas calificaron los contenidos de las notas seleccionadas (véase Anexo A2).

\section{Resultados}

La Tabla 1 muestra las categorías de inseguridad migratoria y los niveles de análisis del contenido de las mismas. De acuerdo con los resultados, la categoría peligro obtuvo el mayor puntaje de mediatización al alcanzar la cifra de 100 puntos seguida de la categoría discriminación con 40 punto de mediatización.

Ambas categorías reflejan el significado de la inseguridad migratoria puesto que el peligro y la discriminación son dos fases permanentes de la espiral violenta hacia quienes transitan por México y se dirigen hacia los Estados Unidos de América.

Tabla 1. Índice de Mediatización de la Inseguridad Migratoria

\begin{tabular}{lcccccc}
\hline Inseguridad & $\begin{array}{c}\text { Valor } \\
\text { acumulado }\end{array}$ & Contextualización & Enmarcado & Intensificación & Total & Interpretación \\
\hline Nulidad & 0 & 0 & 0 & 0 & 0 & $\begin{array}{l}\text { Las noticias seleccionadas } \\
\text { incluyen mediatizaciones que no } \\
\text { pueden ubicarse en un nivel de } \\
\text { nulidad. }\end{array}$ \\
\hline Agresión & 1 & $1(1)=1$ & $1(0)=0$ & $1(0)=0$ & 1 & $\begin{array}{l}\text { La fase de agresión sólo incluyó un } \\
\text { caso contextualizado. }\end{array}$ \\
\hline Injuria & 0 & $2(0)=0$ & $2(0)=0$ & $2(0)=0$ & 0 & $\begin{array}{l}\text { Las noticias seleccionadas no } \\
\text { incluyen la injuria mediatizada en } \\
\text { sus contenidos. }\end{array}$ \\
\hline
\end{tabular}




\section{http://revistainvestigacionacademicasinfrontera.com}

\begin{tabular}{|c|c|c|c|c|c|c|}
\hline Injusticia & $3+3=6$ & $3(1)=3$ & $3(2)=6$ & $3(0)=0$ & 15 & $\begin{array}{l}\text { Dos noticias presentan contenidos } \\
\text { relativos a la injusticia }\end{array}$ \\
\hline Ansiedad & 4 & $4(1)=4$ & $4(2)=8$ & $4(3)=12$ & 28 & $\begin{array}{l}\text { Sólo un caso de las once noticias } \\
\text { incluyó a la ansiedad } \\
\text { contextualizada, enmarcada e } \\
\text { intensificada. }\end{array}$ \\
\hline Peligro & $\begin{array}{c}5+5+5+5= \\
20\end{array}$ & $\begin{array}{l}5(1)+5(1)+5 \\
(1)+5(1)=20\end{array}$ & $\begin{array}{l}5(2)+5(2) \\
+5(2)=30\end{array}$ & $\begin{array}{c}5(3)+5(3)= \\
30\end{array}$ & 100 & $\begin{array}{l}\text { Cuatro casos de mediatización } \\
\text { relativa al peligro contextualizado, } \\
\text { enmarcada e intensificado. }\end{array}$ \\
\hline Desesperación & 0 & 0 & 0 & 0 & 0 & $\begin{array}{l}\text { Ningún caso de mediatización de } \\
\text { la desesperación en torno a la } \\
\text { inseguridad migratoria }\end{array}$ \\
\hline Pánico & 7 & $7(1)=7$ & $7(2)=14$ & $7(0)=0$ & 28 & $\begin{array}{l}\text { Sólo un caso relativo a la } \\
\text { mediatización del pánico } \\
\text { contextualizado y enmarcado }\end{array}$ \\
\hline Depresión & 0 & 0 & 0 & 0 & 0 & $\begin{array}{l}\text { Ningún caso de depresión } \\
\text { mediatizada en torno a la } \\
\text { inseguridad de migrantes }\end{array}$ \\
\hline Venganza & 0 & 0 & 0 & 0 & 0 & $\begin{array}{l}\text { Ningún caso de mediatización de } \\
\text { venganza relativo a la inseguridad } \\
\text { de migrantes }\end{array}$ \\
\hline Discriminación & $10+10=20$ & $\begin{array}{c}10(1)+10(1)= \\
20\end{array}$ & $10(0)=0$ & $10(0)=0$ & 40 & $\begin{array}{l}\text { Dos caso de mediatización de la } \\
\text { discriminación que sólo fueron } \\
\text { enmarcados por las notas de } \\
\text { prensa. }\end{array}$ \\
\hline Total & 58 & 55 & 58 & 42 & 213 & $\begin{array}{l}\text { Muy baja mediatización de la } \\
\text { inseguridad migratoria. Las } \\
\text { noticias relativas a la inseguridad } \\
\text { migratoria se enfocan en el peligro } \\
\text { como su contenido esencial y el } \\
\text { enmarcado como su sesgo } \\
\text { principal. }\end{array}$ \\
\hline
\end{tabular}

Nota: El valor de cada noticia es determinado por su nulidad $=0$, agresión $=1$, injuria $=2$, injusticia $=3$, ansiedad $=4$, peligro $=5$, desesperación $=6$, pánico $=7$, depresión $=8$, venganza $=9$ y discriminación $=10$. Cada valor es multiplicado por su contextualización $=$ 1 , enmarcado $=2$ e intensificación $=3$ del extracto periodístico. Al final se suman los productos y se establece el Índice de Mediatización de la Inseguridad Migratoria

En contraste las categorías desesperación, depresión, venganza no son siquiera mencionadas por las notas de prensa. Llaman la atención la ausencia de mediatización de las noticias de estas categorías puesto que parecen indicar que en México, los periódicos de circulación nacional, durante el periodo de análisis elegido, no reportan los sentimientos de desesperación, depresión y venganza de los implicados en la inseguridad migratoria, las opiniones y análisis de los expertos no parecen considerar éstas tres emociones y los periodistas no parecen orientar sus entrevistas a éstos afectos. 


\section{http://revistainvestigacionacademicasinfrontera.com}

Al ser la inseguridad un ciclo de emociones, sentimientos o afectos, los periódicos parecen contextualizar, enmarcar o intensificar por igual los contenidos de sus noticias.

A la luz de la Teoría del Establecimiento de la Agenda, los medios de comunicación impresos sesgan los contenidos de sus noticias sobre la inseguridad migratoria contextualizando, enmarcando e intensificando el peligro y la discriminación.

Sin embargo, una vez sumados todos los sesgos, el Índice de Mediatización de la Inseguridad Migratoria (IMIM) alcanzó los 213 puntos ubicándose en un nivel bajo de mediatización. Esto significa que la prensa sesga discretamente los contenidos de sus noticias. La baja mediatización de los periódicos La Jornada y El Universal no sería suficiente para influir en la opinión pública, la clase política, las agendas ciudadanas, política y pública.

Una vez establecidos los ejes y temas de discusión de la agenda de seguridad pública, la estimación de sus relaciones se llevó a cabo considerando sus frecuencias en el orden de revisión establecidos por los medios impresos y de acuerdo a sus encuadres (véase Tabla 1).

Tabla 1. Descriptivos de la matriz de análisis de contenido

\begin{tabular}{|c|c|c|c|c|c|c|c|c|}
\hline $\mathbf{S}$ & & $\mathbf{M}$ & D & $\mathbf{S}$ & $\mathrm{C}$ & Contextualización C1 & Enmarcado C2 & Propaganda $(\mathrm{C} 3)$ \\
\hline S1 & Inseguridad & 1,78 & 1,23 & 1,84 & 1,35 & $\left\{\mathrm{X}^{2}=13,2(14 \mathrm{gl}) \mathrm{p}<, 01\right\}$ & & \\
\hline S2 & Agresión & 7,23 & 1,35 & 1,69 & 1,56 & $\left\{X^{2}=10,2(14 \mathrm{gl}) \mathrm{p}<, 01\right\}$ & & \\
\hline S3 & Injuria & 6,46 & 1,98 & 1,73 & 1,48 & & $\left\{\mathrm{X}^{2} 14,2=12(\mathrm{gl}) \mathrm{p}<, 01\right\}$ & \\
\hline S4 & Explotación & 5,95 & 1,78 & 1,72 & 1,93 & $\left\{\mathrm{X}^{2}=12,1(13 \mathrm{gl}) \mathrm{p}<, 01\right\}$ & & \\
\hline S5 & Ansiedad & 4,30 & 1,34 & 1,54 & 1,30 & & $\left\{\mathrm{X}^{2}=14,2(18 \mathrm{gl}) \mathrm{p}<, 01\right\}$ & \\
\hline S6 & Peligro & 4,41 & 1,16 & 1,46 & 1,35 & $\left\{\mathrm{X}^{2}=16,1(10 \mathrm{gl}) \mathrm{p}<, 01\right\}$ & & \\
\hline S7 & Desesperación & 4,28 & 1,71 & 1,34 & 1,32 & & $\left\lceil\mathrm{X}^{2}=17,8(19 \mathrm{gl}) \mathrm{p}<, 01\right\}$ & \\
\hline S8 & Pánico & 6,43 & 1,96 & 1,21 & 1,13 & & & $\left\{\mathrm{X}^{2}=14,6(13 \mathrm{gl}) \mathrm{p}<, 01\right\}$ \\
\hline S9 & Depresión & 5,19 & 1,75 & 1,14 & 1,12 & & $\left\lceil\mathrm{X}^{2}=12,1(15 \mathrm{gl}) \mathrm{p}<, 01\right\}$ & \\
\hline S10 & Venganza & 6,21 & 1,63 & 1,45 & 1,84 & & & $\left\{\mathrm{X}^{2}=12,8(14 \mathrm{gl}) \mathrm{p}<, 01\right\}$ \\
\hline S11 & Discriminación & 5,34 & 1,54 & 1,97 & 1,84 & & $\left\{\mathrm{X}^{2}=14,2(16 \mathrm{gl}) \mathrm{p}<, 01\right\}$ & \\
\hline
\end{tabular}

$\mathrm{S}=$ Subcategoría, $\mathrm{M}=$ Media, $\mathrm{D}=$ Desviación, $\mathrm{S}=$ Sesgo, $\mathrm{C}=$ Curtosis, $\mathrm{C}=$ Categoría

Fuente: Elaborada con los datos del estudio

A la luz del ciclo de la inseguridad, el IMIM parece indicar que la inseguridad migratoria se encuentra en el inicio de la fase de peligro. Este hallazgo es relevante a la luz de las políticas públicas. Dado que la mediatización indica que la inseguridad migratoria se ubica al principio 


\section{http://revistainvestigacionacademicasinfrontera.com}

de la quinta fase del ciclo, entonces será posible revertir la tendencia al reducir los riesgos con la presencia de las fuerzas públicas.

En tal sentido, la coerción de la policía y el ejército en torno al combate de la inseguridad migratoria estaría justificada al menos en términos mediáticos.

No obstante, el ciclo de la inseguridad pública es sumamente complejo. El IMIM recaba dicha complejidad al advertir que mientras en algunas fases del ciclo la prensa no reporta sucesos o hechos relacionados, en otras fases, la prensa concentra sus contextualizaciones, enmarcados e intensificaciones para influir en la opinión pública.

Cabe señalar que el ciclo de la inseguridad y su correspondiente índice sólo explican la dimensión socio-psico-mediática y sus efectos en la opinión del individuo, principalmente sus percepciones, valores, creencias, actitudes y conocimientos. Si ambos explicaran las habilidades, intenciones y conductas de prevención o defensa contra la delincuencia a partir de su grado de información a través de la prensa, entonces los valores de ponderación se invertirían evidenciando una alta mediatización de la desesperación, la depresión y la venganza. En las categorías de análisis se incluirían la indefensión y el suicidio relacionados con la inseguridad migratoria. En consecuencia, la Teoría de la Indefensión Aprendida y la Teoría de la Depresión Suicida explicarían con mayor profundidad los procesos psicológicos como efectos de la inseguridad migratoria reportados por los medios impresos.

Una vez establecidas las relaciones de contingencia entre las categorías y las subcategorias, se procedió a estimar, observar y analizar su estructura, considerando los marcos teóricos y conceptuales que aluden a un fenómeno social de establecimiento de una agenda común a sectores públicos y privados, actores políticos y sociales que los medios impresos parecen al menos contribuir a que tal proceso se reproduzca (véase Figura 1). 
Núm. 28

ISSN: 2007-8870

\section{http://revistainvestigacionacademicasinfrontera.com}

Figura 1. Estructural nodal categórica exploratoria

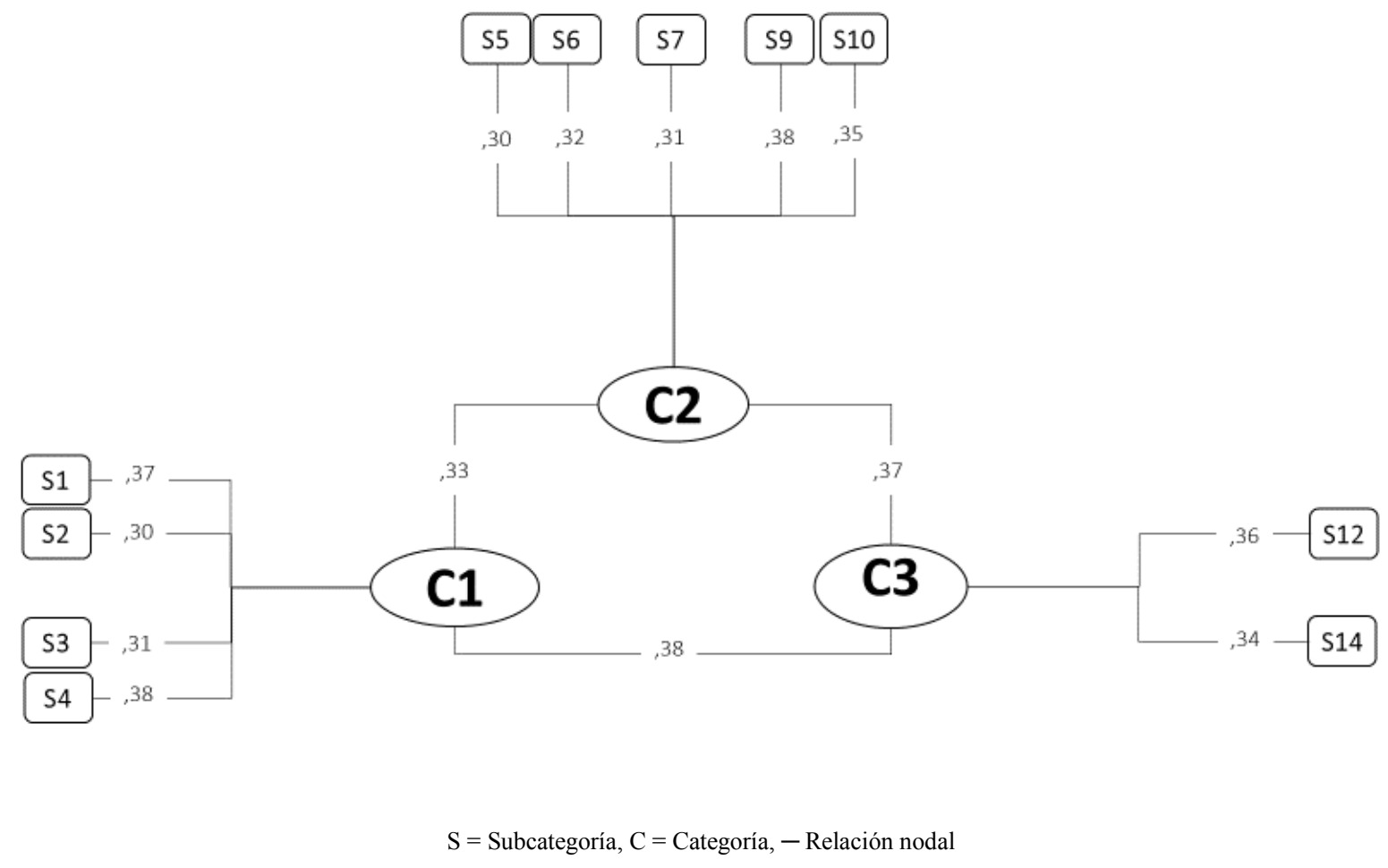

Fuente: Elaborada con los datos del estudio

Es posible apreciar una relación nodal prevaleciente entre el enmarcado de las noticias relativas a la administración de la seguridad migratoria respecto a las subcategorías de injuria, ansiedad, desesperación, depresión y desesperación, aunque otras relaciones nodales se observan con respecto a las categorías de contextualización y propaganda, extremos de cobertura mediática entre los medios impresos consultados y evaluados.

\section{Conclusión}

El presente estudio ha establecido un ciclo y un índice en torno a la mediatización de la inseguridad migratoria para explicar el sesgo de los medios impresos en torno a la problemática. 


\section{http://revistainvestigacionacademicasinfrontera.com}

Debido a que se utilizó la Teoría del Establecimiento de la Agenda para orientar la investigación, tanto las categorías incluidas en el ciclo como la ponderación de cada una de ellas y su posterior estimación con miras al establecimiento del índice, fueron enfocados en los procesos sociopsicológicos más que en los procesos psicológicos como efectos del sesgo informativo y la situación de inseguridad.

La diferencia entre los procesos sociopsicológico y los efectos psicológicos es sustancial.

De acuerdo con la Teoría del Establecimiento de la Agenda, los procesos sociopsicológicos son causa y efecto de la inseguridad migratoria. Tal es el caso de la discriminación, esta categoría, según la prensa, alude a la gota que derramó la espiral de la violencia en un país con desigualdad e injusticia. Es decir, el problema de inseguridad migratoria no se debe al maltrato, robo, extorsión, violación o asesinato que sufren los migrantes, sino se debe a que éstos no tienen manera de responder efectivamente ante estas amenazas. La prensa considera que la civilidad y la prevención del delito serían menos efectivas ante los mecanismos de justicia; denuncia, enjuiciamiento y condena de los delincuentes.

En contraste, los procesos psicológicos son considerados por la teoría como efectos y evidencias en torno a los cuales la prensa sesga la información para convertir a la inseguridad en una gota que derramó la descomposición social y la necesidad de reconstruir el tejido social a partir de la reconciliación nacional, la elección legitima del presidente, un nuevo proyecto de Estado y la inversión en educación para transformar los valores ciudadanos.

Por ello, si se ponderan psicológicamente las noticias seleccionadas para demostrar los efectos de la mediatización en torno a la inseguridad migratoria, se concluiría que la psique del individuo es la solución a la problemática reportada por los medios impresos. Al obtener las habilidades requeridas para inocular la mediatización negativa, los lectores de los periódicos seleccionarían información para tomar decisiones de prevención del delito y cuidado personal más que el cuestionamiento a los medios impresos y sus notas relativas a la inseguridad migratoria. El contenido de dicha inoculación tendría un contenido discriminatorio hacia quienes han sido mediatizados como los delincuentes que causan la inseguridad migratoria.

\section{Referencias}

Briñol, P., Gallardo, I., Horcajo, J., De la Corte, L., Valle, C. y Díaz, D. (2004). Afirmación, confianza y persuasión. Psicothema. 16, 27-31

Cacioppo, J. \& Petty, R. (1989). Effects of message repetition on argument processing, recall and persuasion. Basic and Applied Social Psychology. 10, 3-12 


\section{http://revistainvestigacionacademicasinfrontera.com}

Cacioppo, J., Petty, R., Feng, C. \& Rodríguez, R. (1986). Central and peripheral routes to persuasion: individual difference perspective. Journal of Personality and Social Psychology. 51 (5), 1032-1043

Cervantes, C. (1999). La sociología de las noticias como vía para renovar la investigación en la línea agenda-setting: revisión de interpretaciones. Comunicación y Sociedad. 36, 133-152

Chihú, A. (2011). El Framing del spot político. México: UAM-Porrúa

De León, S. (2008). Notas para una exploración teórica sobre los estudios de producción de comunicación mediática (periodismo, opinión pública y comunicación política). Comunicación y Sociedad. 9, 145-173

Figueras, M. (2008). Mediación social en adolescentes femeninas: revistas juveniles y grupos de iguales. Mediaciones Sociales. 2 (1), 115-132

Francisco, M., García, M. y Maya, I. (2001). El efecto amortiguador del apoyo social sobre la depresión en un colectivo de inmigrantes. Psicothema. 13, 605-610

García, J. (2007). El comportamiento de la prensa durante los conflictos de Kosovo e Irak. Tesis de Doctorado. Universidad de Granada

García, M., Martínez, M. y Albar, M. (2002). La elección de fuentes de apoyo social entre inmigrantes. Psicothema. 14, 369-374

Gunter, B. (2008). Media violence: Is there a case for causality? American Behavioral Scientist. 51 (8), 1061-1022

Gutiérrez, A. (2004). Discursos juveniles sobre inmigración: un análisis psicosociológico en estudiantes. Psicothema. 16, 384-390

Ibarra, A. (2001). La investigación en comunicación masiva y comportamiento social: una visión de su historia y concepción. Comunicación y Sociedad. 40, 11-64 


\section{http://revistainvestigacionacademicasinfrontera.com}

Igartua, Juan., Muñiz, Carlos., Otero, José., Cheng, Lifen y Gómez, José. (2008). Recepción en impacto sociocognitivo de las noticias sobre inmigración. Revista de Psicología Social. 23, 3-16

Kondratieff, N. (1920/2004). The world economy and its conjunctures during and after the war. Moscú: IKF

Lozano, M. (2004). Aspectos psicológicos, sociales y jurídicos del desplazamiento forzoso. Acta Colombiana de Psicología. 12, 103-119

Luengo, M. (2009). Desde los "efectos" mediáticos hasta la influencia cultural: fundamentos analíticos para la interpretación simbólica de los medios. Análisis. 39, 113-129

McCombs. M. (1972). The agenda-setting function of mass media. The public Opinion Quarterly. 36, 176-187

Muñiz, C. (2007). Encuadres noticiosos e inmigración: del análisis de los contenidos al estudio de los efectos mediáticos. Tesis de Doctorado. Universidad de Salamanca

Obregón, R., Arroyave, J. y Milena, M. (2009). Cubrimiento periodístico de la gestión del riesgo en la subregión andina. Discursos periodísticos y perspectivas de la comunicación para el cambio social. Perú: Comunidad Andina

Penalva, C. (1999). La selección de noticias como indicador de desigualdad entre naciones. Papers. 59, 155-172

Petty, R. \& Cacioppo, J. (1986a). The elaboration likelihood model of persuasion. Advances in Experimental Psychology. 19, 123-183

Petty, R. \& Cacioppo, J. (1986b). Communication and persuasion: central peripheral routes to attitude change. New York: Springer-Verlag

Pineda, A. (2007). ¿Todo es propaganda? El propagandismo o monismo propagandístico como límite superior de la teoría de la propaganda. Comunicación. 5, 415-436

Sartori, G. (1997). Homo videns. La sociedad teledirigida. México: Taurus 
Núm. 28

\section{http://revistainvestigacionacademicasinfrontera.com}

Serrano, M. (1986). La producción social de la comunicación. Madrid: Alianza

Sobrados, M. y Muñoz, P. (2009). El mediador intercultural de los medios de comunicación: una apuesta por el cambio social. Mediaciones Sociales. 5, 41-60

Ugarte, A., Menéndez, T. y Cuesta, U. (2009). Prensa escrita y salud en Madrid. España: Universidad Complutense de Madrid

Vázquez, A. (2004). Más allá de Habermans: la realidad de los medios de comunicación. Comunicación y Sociedad. 2, 247-273 
Núm. 28

ISSN: 2007-8870

\section{http://revistainvestigacionacademicasinfrontera.com}

\section{Anexo}

Tabla 1A. La mediatización de la Inseguridad Migratoria

\begin{tabular}{|c|c|c|c|c|c|c|c|c|c|c|}
\hline 言 & $\sum_{\Sigma}^{\infty}$ & 苟 & 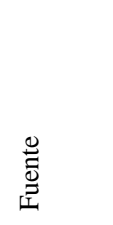 & $\begin{array}{l}\stackrel{\frac{\pi}{0}}{0} \\
\stackrel{0}{0} \\
z\end{array}$ & 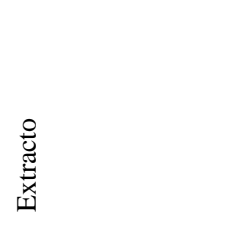 & 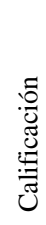 & 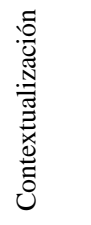 & 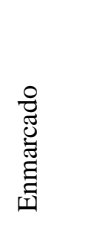 & 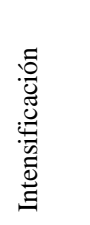 & 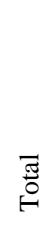 \\
\hline 2011 & Septiembre & 6 & $\begin{array}{l}\text { La } \\
\text { Jornada }\end{array}$ & $\begin{array}{l}\text { ¿Nueva } \\
\text { estrategia } \\
\text { Migratoria? }\end{array}$ & $\begin{array}{l}\text { Las muertes en la } \\
\text { frontera } \\
\text { disminuyeron de } \\
234 \text { a } 168 \text { en éste } \\
\text { año fiscal y eso de } \\
\text { debe, según Bersain } \\
\text { a que han enviado el } \\
\text { mensaje de que la } \\
\text { frontera es mucho } \\
\text { más fuerte con la } \\
\text { presencia de los } \\
\text { agentes. }\end{array}$ & 1 & $\begin{array}{l}1(1)= \\
1\end{array}$ & $\begin{array}{l}1(0)= \\
0\end{array}$ & $\begin{array}{l}1(0)= \\
0\end{array}$ & 2 \\
\hline 2011 & Septiembre & 6 & $\begin{array}{l}\text { La } \\
\text { Jornada }\end{array}$ & $\begin{array}{l}\text { ¿Nueva } \\
\text { estrategia } \\
\text { Migratoria? }\end{array}$ & $\begin{array}{l}\text { Desde la década de } \\
1990 \quad(. .) \text { los } \\
\text { indocumentados se } \\
\text { incrementaron a } 12 \\
\text { millones, de los } \\
\text { cuales cerca de } 7 \\
\text { millones son } \\
\text { mexicanos. Había } \\
\text { trabajo y por eso } \\
\text { valía la pena } \\
\text { arriesgarse, pues las } \\
\text { condiciones } \\
\text { laborales en México } \\
\text { eran lamentables. }\end{array}$ & 4 & $\begin{array}{l}4(1)= \\
4\end{array}$ & $\begin{array}{l}4(2)= \\
8\end{array}$ & $\begin{array}{l}4(3)= \\
12\end{array}$ & 28 \\
\hline 2012 & Marzo & 19 & $\begin{array}{l}\text { La } \\
\text { Jornada }\end{array}$ & $\begin{array}{l}\text { Programa } \\
\text { piloto de } \\
\text { repatriación } \\
\text { de migrantes } \\
\text { desde Estados } \\
\text { Unidos } \\
\text { costara } \quad 50 \\
\text { millones de } \\
\text { dólares: } \\
\text { Instituto }\end{array}$ & $\begin{array}{l}\text { Se trata, explicaron } \\
\text { ambos funcionarios } \\
\text { de romper la cadena } \\
\text { de corrupción en la } \\
\text { frontera común para } \\
\text { evitar con ello que } \\
\text { los deportados en } \\
\text { esa zona sean } \\
\text { víctimas de las } \\
\text { organizaciones } \\
\text { criminales, quienes } \\
\text { "los enganchan" }\end{array}$ & 5 & $\begin{array}{l}5(1)= \\
5\end{array}$ & $\begin{array}{l}5(0)= \\
0\end{array}$ & $\begin{array}{l}5(0)= \\
0\end{array}$ & 10 \\
\hline
\end{tabular}


(Julio- Diciembre 2018)

Revista de Investigación

Año 11.

Académica sin Frontera

Núm. 28

ISSN: 2007-8870

\section{http://revistainvestigacionacademicasinfrontera.com}

\begin{tabular}{|c|c|c|c|c|c|c|c|c|c|c|}
\hline & & & & $\begin{array}{l}\text { Nacional de } \\
\text { Migración }\end{array}$ & $\begin{array}{l}\text { para el trasiego de } \\
\text { drogas, la trata y la } \\
\text { extorsión entre } \\
\text { otros. }\end{array}$ & & & & & \\
\hline 2012 & Febrero & 29 & $\begin{array}{l}\text { La } \\
\text { Jornada }\end{array}$ & $\begin{array}{l}\text { Se piensa que } \\
\text { la migración } \\
\text { externa es } \\
\text { causa de la } \\
\text { inseguridad: } \\
\text { CONAPRED }\end{array}$ & $\begin{array}{l}80 \text { por ciento de la } \\
\text { población general } \\
\text { opina que los } \\
\text { derechos de las } \\
\text { personas migrantes } \\
\text { no se respetan o se } \\
\text { respetan poco (...) } \\
\text { el desempleo, } \\
\text { seguido de la } \\
\text { discriminación e } \\
\text { inseguridad fueron } \\
\text { considerados los } \\
\text { principales } \\
\text { problemas }\end{array}$ & 10 & $\begin{array}{l}10(1) \\
=10\end{array}$ & $\begin{array}{l}10(0= \\
=0\end{array}$ & $\begin{array}{l}10(0) \\
=0\end{array}$ & 20 \\
\hline 2012 & Febrero & 29 & $\begin{array}{l}\text { La } \\
\text { Jornada }\end{array}$ & $\begin{array}{l}\text { Se piensa que } \\
\text { la migración } \\
\text { externa es } \\
\text { causa de la } \\
\text { inseguridad: } \\
\text { CONAPRED }\end{array}$ & $\begin{array}{l}\text { En la población en } \\
\text { general, casi } 7 \text { de } \\
\text { cada } \\
\text { encuestados } \\
\text { consideran que los } \\
\text { inmigrantes } \\
\text { proporcionan } \\
\text { divisiones y } 27 \text { por } \\
\text { ciento no aceptaría } \\
\text { que en su casa } \\
\text { vivieran } \\
\text { extranjeros. }\end{array}$ & 10 & $\begin{array}{l}10(1) \\
=10\end{array}$ & $\begin{array}{l}10(0= \\
=0\end{array}$ & $\begin{array}{l}10(0) \\
=0\end{array}$ & 20 \\
\hline 2012 & Febrero & 29 & $\begin{array}{l}\text { La } \\
\text { Jornada }\end{array}$ & $\begin{array}{l}\text { Se piensa que } \\
\text { la migración } \\
\text { externa es } \\
\text { causa de la } \\
\text { inseguridad: } \\
\text { CONAPRED }\end{array}$ & $\begin{array}{l}\text { Por el riesgo de que } \\
\text { las autoridades } \\
\text { mexicanas los } \\
\text { expulsen del país y } \\
\text { el desconocimiento } \\
\text { de sus derechos, } \\
\text { éste grupo de } \\
\text { población no acude } \\
\text { a denunciar los } \\
\text { abusos de que son } \\
\text { objetos. }\end{array}$ & 3 & $\begin{array}{l}3(0)= \\
0\end{array}$ & $\begin{array}{l}3(2)= \\
6\end{array}$ & $\begin{array}{l}3(0)= \\
0\end{array}$ & 9 \\
\hline 2012 & Febrero & 20 & $\begin{array}{l}\text { La } \\
\text { Jornada }\end{array}$ & $\begin{array}{l}\text { México no es } \\
\text { único } \\
\text { responsable } \\
\text { de maltrato a } \\
\text { migrantes del } \\
\text { sur }\end{array}$ & $\begin{array}{l}\text { En ninguna parte } \\
\text { del mundo "se da } \\
\text { una situación en la } \\
\text { cual el migrante va } \\
\text { caminando entre } \\
\text { algodones desde su } \\
\text { país natal hasta el } \\
\text { de destino. No hay }\end{array}$ & 5 & $\begin{array}{l}5(1)= \\
5\end{array}$ & $\begin{array}{l}5(2)= \\
10\end{array}$ & $\begin{array}{l}5(3)= \\
15\end{array}$ & 35 \\
\hline
\end{tabular}


(Julio- Diciembre 2018)

"El saber de mis hijos
hará mi grandeza"

Revista de Investigación

Año 11.

Académica sin Frontera

Núm. 28

ISSN: 2007-8870

\section{http://revistainvestigacionacademicasinfrontera.com}

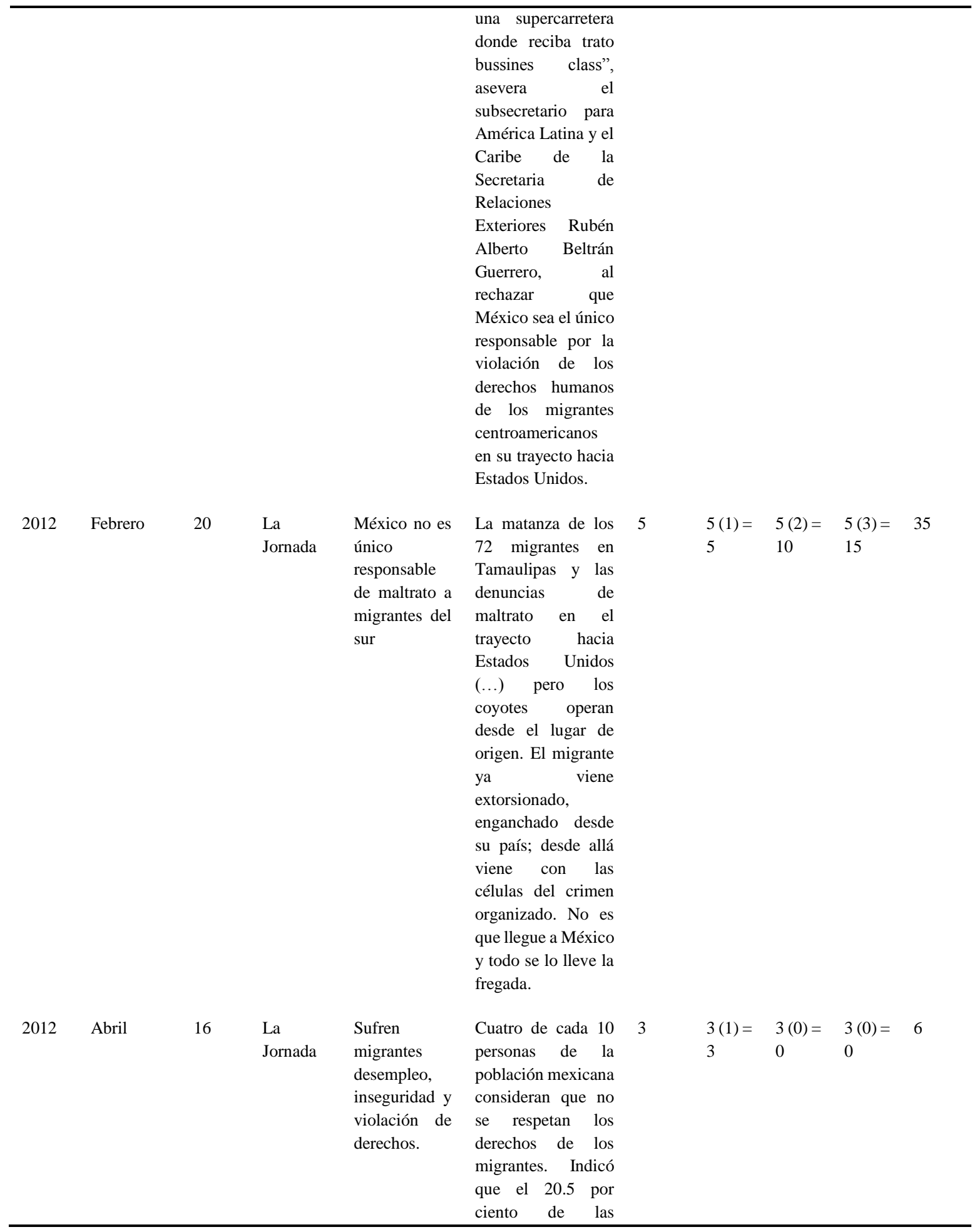


Revista de Investigación

Año 11.

Académica sin Frontera

Núm. 28

ISSN: 2007-8870

\section{http://revistainvestigacionacademicasinfrontera.com}

\begin{tabular}{|c|c|c|c|c|c|c|c|c|c|c|}
\hline & & & & & $\begin{array}{l}\text { personas migrantes } \\
\text { considera que el } \\
\text { principal problema } \\
\text { que enfrentan por } \\
\text { su condición } \\
\text { migratoria es la } \\
\text { discriminación; } \\
\text { sólo por debajo del } \\
23 \text { por ciento que } \\
\text { opina que son las } \\
\text { situaciones que se } \\
\text { relacionan con el } \\
\text { desempleo, } \\
\text { mientras que } 17 \text { por } \\
\text { ciento respondió } \\
\text { que es la } \\
\text { inseguridad. }\end{array}$ & & & & & \\
\hline 2012 & Abril & 16 & $\begin{array}{l}\text { La } \\
\text { Jornada }\end{array}$ & $\begin{array}{l}\text { Mantiene } \\
\text { Solalinde } \\
\text { demandas } \\
\text { urgentes a } \\
\text { favor de } \\
\text { migrantes }\end{array}$ & $\begin{array}{l}\text { Los desequilibrios } \\
\text { económicos, la } \\
\text { desigualdad social y } \\
\text { la falta de } \\
\text { autoridades en sus } \\
\text { lugares de origen } \\
\text { son las causas que } \\
\text { provocan } \\
\text { migración. }\end{array}$ & 5 & $\begin{array}{l}5(1)= \\
5\end{array}$ & $\begin{array}{l}5(2)= \\
10\end{array}$ & $\begin{array}{l}5(0)= \\
0\end{array}$ & 20 \\
\hline 2012 & Febrero & 15 & $\begin{array}{l}\text { El } \\
\text { Universal }\end{array}$ & $\begin{array}{l}\text { Migrantes de } \\
\text { Hidalgo } \\
\text { permanecen } \\
\text { en EU por } \\
\text { miedo e } \\
\text { inseguridad }\end{array}$ & $\begin{array}{l}\text { Migrantes prefieren } \\
\text { quedarse en la } \\
\text { Unión Americana, } \\
\text { ya que después es } \\
\text { más difícil regresar } \\
\text { a Estados Unidos } \\
\text { debido a las duras } \\
\text { leyes migratorias } \\
\text { como las de } \\
\text { Arizona y Alabama. }\end{array}$ & 7 & $\begin{array}{l}7(1)= \\
7\end{array}$ & $\begin{array}{l}7(2)= \\
14\end{array}$ & $\begin{array}{l}7(0)= \\
0\end{array}$ & 28 \\
\hline Total & & & & & & 58 & 55 & 58 & 42 & 208 \\
\hline
\end{tabular}

Nota: El valor de cada noticia es determinado por su nulidad $=0$, agresión $=1$, injuria $=2$, injusticia $=3$, ansiedad $=4$, peligro $=5$, desesperación $=6$, pánico $=7$, depresión $=8$, venganza $=9$ y discriminación $=10$. Cada valor es multiplicado por su contextualización $=$ 1 , enmarcado $=2$ e intensificación $=3$ del extracto periodístico. Al final se suman los productos y se establece el Índice de Mediatización de la Inseguridad Migratori 
Núm. 28

ISSN: 2007-8870

\section{http://revistainvestigacionacademicasinfrontera.com}

\section{Como citar este articulo}

Joel Martínez-Bello/ Christian Bucio-Pacheco/ José Alfonso Aguilar-Fuentes/Francisco Javier Rosas-Ferrusca/ Wilfrido Isidro Aldana-Balderas/ Adriana Vanessa Blanes-Ugarte/ Cruz García-Lirios. Estructura nodal exploratoria de la administración de la seguridad migratoria en los medios impresos. Estructura nodal exploratoria de la administración de la seguridad migratoria en los medios impresos. RIASF. Núm. 28, Julio-diciembre (2018), ISSN 2007-8870. pp. xx-xx. 